\title{
Utilizing Fairview as a Bilingual Response to Intervention (RTI): Comprehensive Curriculum Review with Supporting Data
}

\author{
Melissa Ausbrooks-Rusher \\ Lamar University, U.S.A \\ Email: drmelissarusher@live.com \\ Connie Schimmel \\ Milsaps College, U.S.A \\ Sandra Edwards \\ Mississippi School for the Deaf, U.S.A
}

\begin{abstract}
The purpose of this study was to review and critically align the Fairview (FV) reading intervention protocols with research and best practices in ASL/English bilingual education, and to determine its appropriateness across methodological/philosophical delivery options. Results of two action research studies highlight implementation techniques in diverse settings and provide insight into Fairview's viability as a bilingual intervention. Individual student progress results across all five components and summary scores across classrooms demonstrate statistically significant differences in student outcomes from pre to post tests. Progress on the Adapted Dolch and Bridge Lists yielded the most significant differences.
\end{abstract}

Index Terms -ASL, English, bilingual, deaf children, deaf bilingual, language interdependence, RTI

\section{INTRODUCTION \& LITERATURE REVIEW}

Grassroots efforts led by Deaf ${ }^{1}$ educators of students who are deaf or hard of hearing have addressed ineffective pedagogy, leading to the development of training programs that have inspired bilingual education for the deaf for a decade and a half (LaSasso \& Lollis, 2003; Nover, Andrews, Baker, Everhart, \& Bradford, 2002). Numerous empirical studies provide support for methodology (see annotated review in Ausbrooks Rusher, 2012), although many of these are not without debate (Mayer \& Wells, 1996; Mayer \& Akamatsu, 1999; 2003; 2010). Additionally, most bilingual training programs target schools for the deaf rather than broadly addressing the continuum of educational settings. With more than $85 \%$ of deaf or hard of hearing children, aged 6 through 21, in public schools programs, this philosophical option has not been available to most school-aged children who are deaf or hard of hearing, nor to their teachers. Consequently, efforts to cross-institutionalize the methodology have been limited by opposing philosophical trends, variations in teacher training programs, non-standardized curriculum, and pervasive misunderstandings about ASL/English Bilingual Education (Ausbrooks, 2007; DeLana, Gentry, \& Andrews, 2008). Methodological expansion is further impeded by beliefs that public schools cannot possibly emulate the socio-linguistically rich environment needed for adequate implementation (Geeslin, 2007; Myers, 2011). Therefore, training protocols that solely target residential programs have not gained wide popularity. However, one bilingual intervention program, Fairview Learning, has gained increased acceptance in general education environments, positioning itself in every state, across all educational delivery options, and in more than 2,000 classrooms nationwide (Connie Schimmel, personal communication, May, 2010). Due to its scaffolded level of implementation given teacher sign language skills, however, professional debate, outside of the literature, has raised doubts about whether or not it is an appropriate option for bilingual programs. The purpose of this study was to review and critically align the Fairview (FV) reading intervention protocols with research and best practices in ASL/English bilingual education, and to determine its appropriateness across methodological and/or philosophical delivery options. Results of two action research studies highlight implementation techniques in diverse settings and provide insight into Fairview's viability as a bilingual response to intervention.

The Bimodal Bilingual Framework

Cummins' (1979, 2003) Language Interdependence Theory hypothesized that common linguistic proficiencies underlie all languages and proficiencies transfer from one language to the other(s). Language experiences and language

\footnotetext{
1 The term, deaf or hard of hearing, refers to those individuals with severe to profound, or mild to severe hearing losses, respectively. The term, Deaf, refers to those individuals who consider themselves members of the Deaf community and thereby share a language, American Sign Language, and culture. Schools for the deaf refer to institutions, either day or residential schools, specifically designated by their respective states to serve deaf or hard of hearing students.
} 
handling techniques determine educational and linguistic performance, with semilingualism resulting from inadequate language exposure and techniques. Students, whose academic proficiency in the language of instruction is relatively weak, tend to fall further behind, unless the instruction they receive enables them to better comprehend input and participate academically in their classes (Cummins, 2000). Consequently, poor language handling practices in Deaf Education may be to blame for depressed achievement, if these theories are applicable to deaf students. Nover, Christensen, \& Cheng (1998) and Nover \& Moll (1997) emphasized the need to ensure that instructional techniques facilitate language acquisition and capitalize on linguistic repertoire. Their paradigm considers linguistic, cultural, and educational implications more than the sensory disability or the many non-malleable environmental factors uncontrollable by educators (Charrow, 1981; Nover \& Moll, 1997; Padden \& Humphries, 1988). Supporters state that ASL provides the necessary portal for complete, natural, and unrestricted linguistic input and communicative competence (Johnson, Liddell, \& Erting, 1989). The major difficulty, however, is that ASL has no widely-accepted written form; therefore English acquisition is necessary for literacy (Hoffmeister, 2000). Educational programs, proponents argue, should follow additive bilingual models and should consider the unique language abilities of bimodal bilinguals. Nover, Christensen, \& Cheng's (1998) three-tiered framework- signacy (attending/signing), literacy, and oracy- established the model for ASL/English bilingual education.

\section{Potential Constraints to Linguistic Interdependence}

Not all professionals in Deaf Education accept the notion that Cummins' theories apply to deaf students. Opponents' arguments begin with the early language experiences of deaf children. Approximately $90 \%$ of deaf children are born to hearing parents (Johnson, Watkins, \& Rice, 1992; Mitchell \& Karchmer, 2004), and therefore do not experience familial transmission of early ASL (Grosjean, 1998). The school, rather than the home, becomes "the major socializing agent for deaf children," (Padden, 1998, p. 82). Researchers such as Mayer \& Wells (1996) argue that only deaf children of deaf parents can truly claim ASL as their first language. Cummins' theories, which are based on hearing bilinguals who enter school with an existing first language foundation, are negated. Researchers agree that deaf children struggle to acquire a first language due to lack of communicative access. Early-deafened children face significant barriers in their potential acquisition of spoken languages that are not fully accessible to them (Singleton, Supalla, Litchfield, \& Schley, 1998). Lipreading is not a viable option for receiving the complete linguistic code either, for only $30 \%$ of English is visible on the lips (Haskins, 2000). Early acquisition of ASL is problematic as well. Delay in early ASL acquisition often results in severe language deprivation which often continues throughout the childhood years of deaf children, as many hearing families never learn to sign beyond a basic level, thereby excluding the deaf child from many social and familial activities (Andrews, Leigh, Wiener, 2004). Rarely can schools provide adequate immersion to compensate for deficiencies. In addition, many teachers exhibit substandard ASL skills compromising linguistic modeling (Livingston, 1997). Insufficient exposure to social and academic language restricts the deaf child's ability to fully obtain age-appropriate social and academic knowledge (Livingston, 1997).

Another issue central to the controversy over language interdependence regards modality (Mayer \& Wells, 1996; Mayer and Akumatsu, 2003; 2010). English is delivered in spoken or written form and understood through audition or reading. ASL, on the other hand, is a visual-spatial language manually expressed on a three-dimensional plane, and received visually, with no widely-accepted written form. English is processed linearly by the language receiver, one word at a time, while the receiver of ASL input processes multiple signs and other units of meaning simultaneously (Valli \& Lucas, 2000). Mayer and Wells (1996) and Mayer and Akumatsu (2003; 2010) argue that Cummins' theories apply only to languages that occur in the same modality and academic proficiency only transfers when literacy already exists in the first language. Since ASL has no written form, some argue first language literacy is not achievable. Mayer and Wells (1996) and Mayer and Akumatsu (2003) point out that Cummins found no connection between oral language skills in the first language and literacy skills in the second, thus modality constrains dual language acquisition. However, in 2007, Cummins issued a review, The Relationship between American Sign Language Proficiency and English Academic Development: A Review of the Research, where he describes five types of transfer due to common underlying proficiencies- conceptual knowledge, metacognitive and metalinguistic strategies, pragmatic aspects of language use, specific linguistic elements, and phonological awareness.

Linguistic development for bilingual children is complex, dynamic, and individual (Garcia, 2009). As bimodal bilinguals learn both languages, emerging proficiencies progress through stages similar to those of other young bilinguals- early language, potential bilingualism, developing bilingualism and proficient bilingualism (Andrews \& Rusher, 2010). These stages vary from the normative, linear developmental stages of monolingual children. To adequately strengthen these emerging proficiencies, Garcia (2009) suggests that we describe the manner in which the bilingual child translanguages- that is, the extent the child effectively engages in multiple discourse practices with a variety of interlocutors, in various contexts, and for varying purposes. When instructional strategies fail to promote effective translanguaging, reading and language outcomes may suffer (Andrews \& Rusher, 2010).

Additional controversy exists regarding linguistic differences of the two languages (Mayer \& Akumatsu, 2003; 2010; Mayer \& Wells, 1996). Stokoe (1960) initially uncovered these distinctions and fueled the debate regarding the efficacy of ASL as an instructional tool for deaf children (Stokoe, 1976; Valli \& Lucas, 2000). As linguists pointed out, ASL is replete with phonological, morphological, syntactical, semantic, and pragmatic features unique and very different from those of English (Stokoe, 1960, 1976; Valli \& Lucas, 2000). Undoubtedly, the translation process is complex (Mather \& 
Thibeault, 2000). The reader has to alter language modality in addition to considering other linguistic elements when creating semantic approximations (Baker \& Jones, 1998; Frishberg, 2000; Larson, 1994). For deaf ASL/English bilingual readers, linguistic components must be explicitly taught.

While ASL/English bilingual education remains in the early stages of research production, classroom teachers need significant assistance with instructional choices, as evidenced by persistently-depressed student outcome data across all methodological delivery options. While many college-aged deaf adults are proficient bilinguals (Andrews \& Karlin, 1996; Ausbrooks, 2007), almost $60 \%$ of deaf students graduate from high school reading at a fourth grade level or less (Traxler, 2002). At one end of the spectrum are deaf persons who are linguistically incompetent with weak skills in both ASL and English. At the other end, many deaf adults develop sophisticated translanguaging skills, achieving biliteracy post-high school (Ausbrooks, 2007).

Important for users of FV is understanding variation in language handling, especially differences between concurrent and simultaneous delivery of ASL and English. Concurrent approaches ensure ASL and English are presented without any compromise to the complete linguistic code of each language. Separation of language is essential in such approaches and teachers use sophisticated codeswitching and translanguaging strategies to integrate both languages into the entire lesson. For example, a teacher may use printed material to expose English and use ASL for discussion. Another popular strategy is for the teacher to utilize a particular language during a specific part of the lesson. Conversely, using language mixing strategies, such as simultaneous sign and speech, does not place the same emphasis on language separation, but rather differentiates language expression based on the individualized linguistic capital of students in a given instructional period. FV provides flexibility in implementation that allows either philosophical and/or methodological approach to be successfully integrated. FV materials and trainings assist teachers in identifying where teachers and students fall on the linguistic continuum from American Sign Language to English and encourages this designation during instruction.

\section{FAIRVIEW INTERVENTION PROTOCOL}

FV's design incorporates the necessary strategies documented for reading success (National Reading Panel, 2001). Although the five principles of effective reading instruction- comprehension, vocabulary, fluency, phonic, and phonemic awareness - are included (National Reading Panel, 2001), the FV strategies incorporate more. FV emphasizes systematic vocabulary building and reading fluency with the use of the Adapted Dolch and Bridge Lists, but FV also emphasizes the simultaneous need to develop writing (spontaneous written English) and ASL skills. Phonemic awareness is also addressed. Traditional literacy methods are combined into a streamlined, multi-faceted program supported by linguistic and neurological learning research (Lieberman, 2000; Pinker, 1998; Rayner, et.al, 2002.) The instructional model utilizes neurological research and concepts about how the brain organizes and stores information (Dehaene, 2009), as well as recommended and proven methods for successful reading strategies (Dehaene, 2009; Rayner, et. al, 2002). In addition, the program can be used as an individualized RTI or an informal reading inventory. (See http://www.fairviewlearning.com.) A discussion of the protocol and each component follows.

\section{Component 1: Adapted Dolch Words}

Expressive vocabulary (assessed orally or in sign), significantly predicts reading achievement (Easterbrooks, Lederberg, Miller, Bergeron, \& Connor, 2008; Kyle \& Harris, 2006). Skilled readers do not decode individual letters of a word; rote mastery is a prerequisite to reading fluency. FV's Adapted Dolch Word make the traditional Dolch Lists, divided into five grade levels, preprimer through $3^{\text {rd }}$ grade, accessible to emerging bilinguals. Students have multiple options in schematic sign choice; vocabulary translations require semantic approximations, rather than a direct pairing of individual terms (Ausbrooks, 2007). For example, made is a Dolch word which has multiple meanings - I made a present for you; I made my bed; I made money; My brother made me do that; The rain made the grass green. Each meaning requires a different sign for accurate translation. Preset lists with accompanying videotapes, instructional materials and assessment instruments, support direct instruction of this process. The Adapted Dolch Word component exposes children of all competency levels to the ASL lexicon, and provides the initial step in utilizing ASL as an intervening variable for English development. Words common to social language, such as make, now access more sophisticated linguistic skills and academic knowledge as children make semantic connections through conceptually accurate translations. The very nature of multiple meaning decoding and semantic approximation enriches language development, expands metalinguistic awareness, strengthens cognitive flexibility, and increases semantic and pragmatic awareness of concepts (Andrews \& Mason, 1991; Cummins, 2007; Goldman-Meadow \& Mayberry, 2001; Lartz \& Lestina, 1995).

\section{Component 2: Reading Comprehension and the Bridging Process}

"Bridges" are English phrases that are expressed accurately in ASL as a single sign or compound. For example, the English phrase, put out the fire, could be expressed accurately as a single sign, EXTINGUISH, or by one stepping into character and acting out the use of a fire extinguisher or water hose. In either case, the translation is a single sign. Brackets signal to the reader a single semantic unit - [put out the fire] - distinguishing the concept from other words which may be translated individually. Preset lists, with accompanying videotapes, instructional materials and assessment instruments, support direct instruction of this sophisticated codeswitching process termed "bridging." These lists are divided into five grade levels, preprimer through $3^{\text {rd }}$ grade. Pre-set Bridge Lists provide a direct, concrete, and 
systematic process that eases linguistic transfer of content and enhances metalinguistic awareness needed for translation. The process of bridging may begin with students utilizing the pre-set Bridge Lists, but continuity of the technique occurs when teachers and students initiate rich dialogue regarding free and literal linguistic translation. During these discussions and expanded applications, the explicit instruction of the Bridge Lists decreases, as students engage in language play and determine multiple ways to translate single passages of text. This expanded dialogue transforms the metacognitive patterns of the reader, whether teacher or student, as they begin the process of conceptual transfer (Bailes, 2001; Hauser, 2000). Regardless of the manual option used, bridges force a mental and signed codeswitch back to the ASL lexicon.

Component 3: Phonemic Awareness

Skilled deaf readers capitalize on phonological information (Goldman-Meadow \& Mayberry, 2001; McQuarrie \& Parrila, 2009; Syverud, Guardino, \& Selznick, 2009; Wang, Trezek, Luckner, \& Paul, 2008). In fact, "the graphemephoneme conversion radically transforms the child's brain, thus, we now know that phonemes must be explicitly taught," (Dehaene, 2009, p 219). FV integrates phonemic awareness strategies into its protocols to assist deaf readers as they crack the phonemic code of English. Readers learn to identify 21 consonant sounds and 21 vowel patterns, presented in a visually accessible manner, to assist word decoding. By teaching deaf students an awareness of the visual patterns in English phonology, phonemic awareness is developed, irrespective of functional or residual hearing levels. The process, which combines both speech and phonic symbol systems, is based on the Northampton Consonant and Vowel Charts, originally published by a teacher of deaf children (Davis \& Silverman, 1966). Although the process does not include the many exceptions and additions to the phonetic rules of English, it does provide a useful, accessible structure for explicit instruction. The patterns give phonetic significance to the consonants and vowels of the English alphabet without additional markings or symbolic spellings.

\section{Component 4: Literature-Based Instruction}

FV not only recommends structured reading exercises to teach students better comprehension, decoding skills, and the use of contextual clues, but also recognizes the need for contextually-embedded instruction via literature-rich curriculum. FV provides guidance for the application of Adapted Dolch and Bridging strategies during literature-based instruction. Rather than provide a comprehensive reading program, FV supports teachers by recommending a variety of curricular options. This literature-based instruction encourages teachers to select materials appropriate to student need, reading level, maturation, and interest (Schleper, 2002). In the literature-based instruction component, the Adapted Dolch and Bridge Lists are utilized or teachers may require more autonomy from students by requiring them to develop their own translations in order to justify semantic and schematic choices, thereby scaffolding students in their metalinguistic and metacognitive development. A variety of age appropriate reading materials is encouraged.

\section{Component 5: ASL Development and Spontaneous Written English}

Utilized in early education and special education programs, language experience stories are commonly accepted as a tool for emerging literacy in children (Dixon, 1990; Mayer, 2007; Schleper, 2002; Sidelnick, M. \& Svoboda, M, 2000). FV utilizes two specific types of interventions. The first intervention involves students telling personal stories to the ASL instructor, who then retells the stories modeling proper ASL. Students then sign their stories again, implementing proper ASL structure. The second intervention occurs during other class times when students translate their ASL stories into written English or dictate spontaneous and personal short stories to their teachers. After these stories are recorded, they are edited into more structured English by the teachers, and titled, copied, and illustrated by the students. These intervention techniques are cognitively challenging and require higher order thinking skills, such as evaluating, inferring, generalizing, and classifying, and, as skills progress, integrated academic content. Instructors use the language experience stories and drawings to combine induced imagery, experiential memory, self-expression, and emotion to improve cognition and word memory.

\section{Fairview as an Informal Reading Inventory}

Teachers often complain of unfair testing and curriculum for students who are deaf or hard of hearing, especially in reading comprehension (Trezek, Wang, \& Paul, 2010). Fairview offers multiple assessment measures and interventions that can be implemented by teachers of all manual philosophies and abilities, ranging from English-based sign systems to fluent ASL users. The FV instruments, rubrics, and tools provide a user-friendly informal reading inventory which is easy for teachers to use, no matter what their English/ASL comfort levels. FV, constructed for deaf students, allows a common starting point for students at all grade levels. The conceptually accurate sign interventions provide a transition to ASL, enabling implementation without rigid and comprehensive philosophical change. Furthermore, the five FV components create a comprehensive intervention which addresses all three domains of bimodal bilingual language ability- signacy, literacy, and oracy,

\section{Fairview as a Response to Intervention}

Response to Intervention (RTI) is a process first recommended in 2004 with the reauthorization of Public Law 94142, the Individuals with Disabilities Education Act (IDEA). The actual statutory language states: 'In determining whether a child has a specific learning disability, a local education agency may use a process that determines if the child responds to scientific, research-based intervention as a part of the evaluation procedures' (Bradley, Danielson, Doolittle, 2007; Kame'enui, 2007). Throughout the nation a 3-tier framework is often used to operationalize the new legislation. Tier 1 includes quality classroom instruction, Tier 2 involves supplemental instruction, and Tier 3 requires intensive 
interventions specifically designed to meet the individual needs of students The components of the RTI protocol have been shown in other randomized controlled studies to improve most students' academic achievement. (Fuchs, Fuchs, Compton, Bouton, Caffrey, \& Hill, 2007. The use of FV as a bilingual RTI combines high quality, culturally and linguistically responsive instruction, assessment, and evidence-based intervention. Figure 1 provides the summary schematic. For specific tier strategies, please refer to http://fairviewlearning.com.

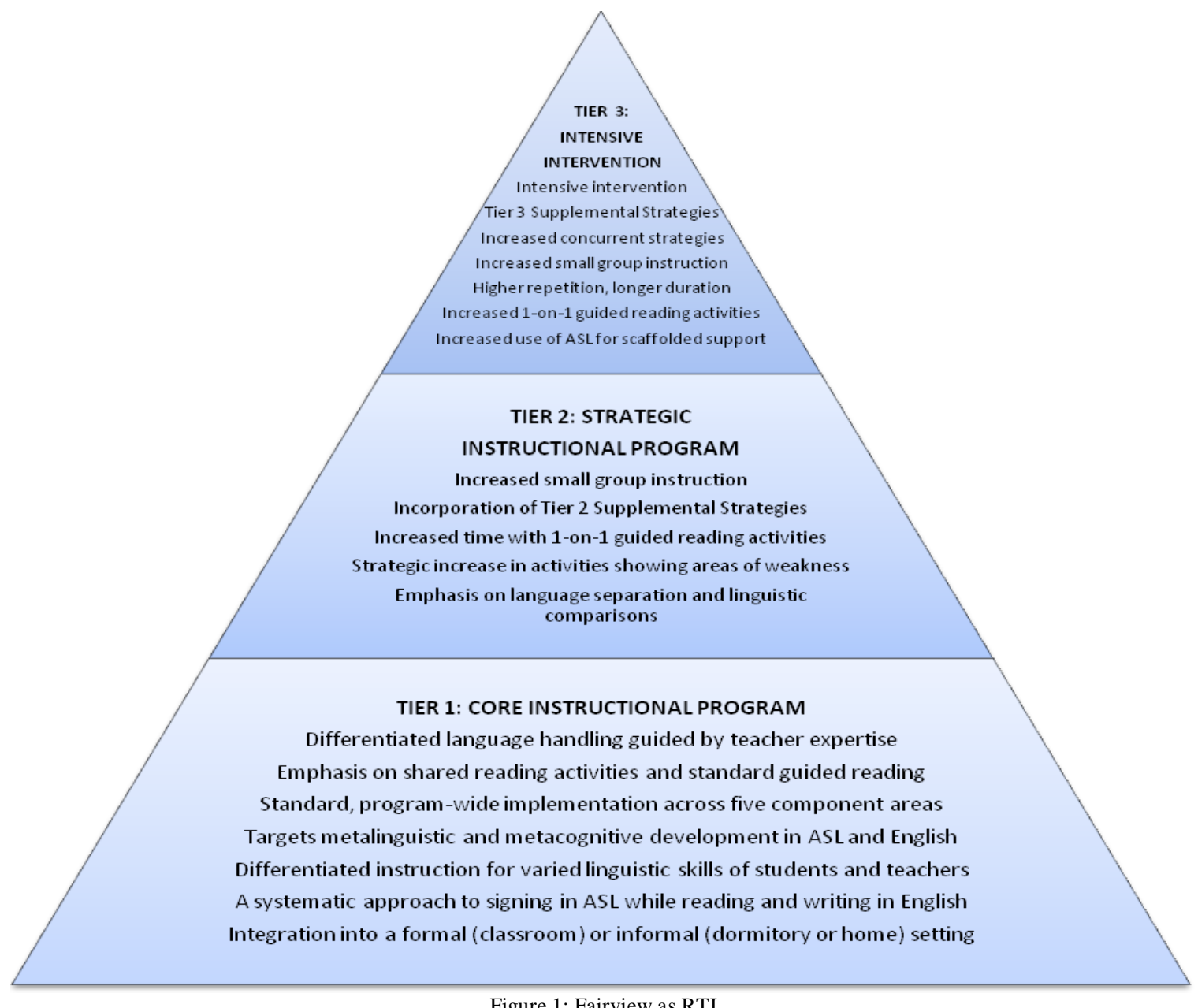

Figure 1: Fairview as RTI

\section{RESEARCh DESIGN}

Two action research studies highlight the effective implementation of the FV protocol. Two teachers in contrasting school settings utilized FV as Response to Intervention (RTI) to address concerns of their at risk students who were reading below grade level. Teacher A, a teacher at a residential school, utilized Fairview components with her $4^{\text {th }}, 5^{\text {th }}$, and $6^{\text {th }}$ grade classes. Teacher B, a teacher in a self-contained public middle school program utilized the components with her $7^{\text {th }}$ grade classes. Pre and post evaluation of Fairview intervention assessments determined skill progression. Additional academic and reading results are provided. Table 1 provides demographic information for the diverse samples. Although all of the students in the study used manual sign systems, most were not proficient in ASL. 
TABLE 1:

DEMOGRAPHICS

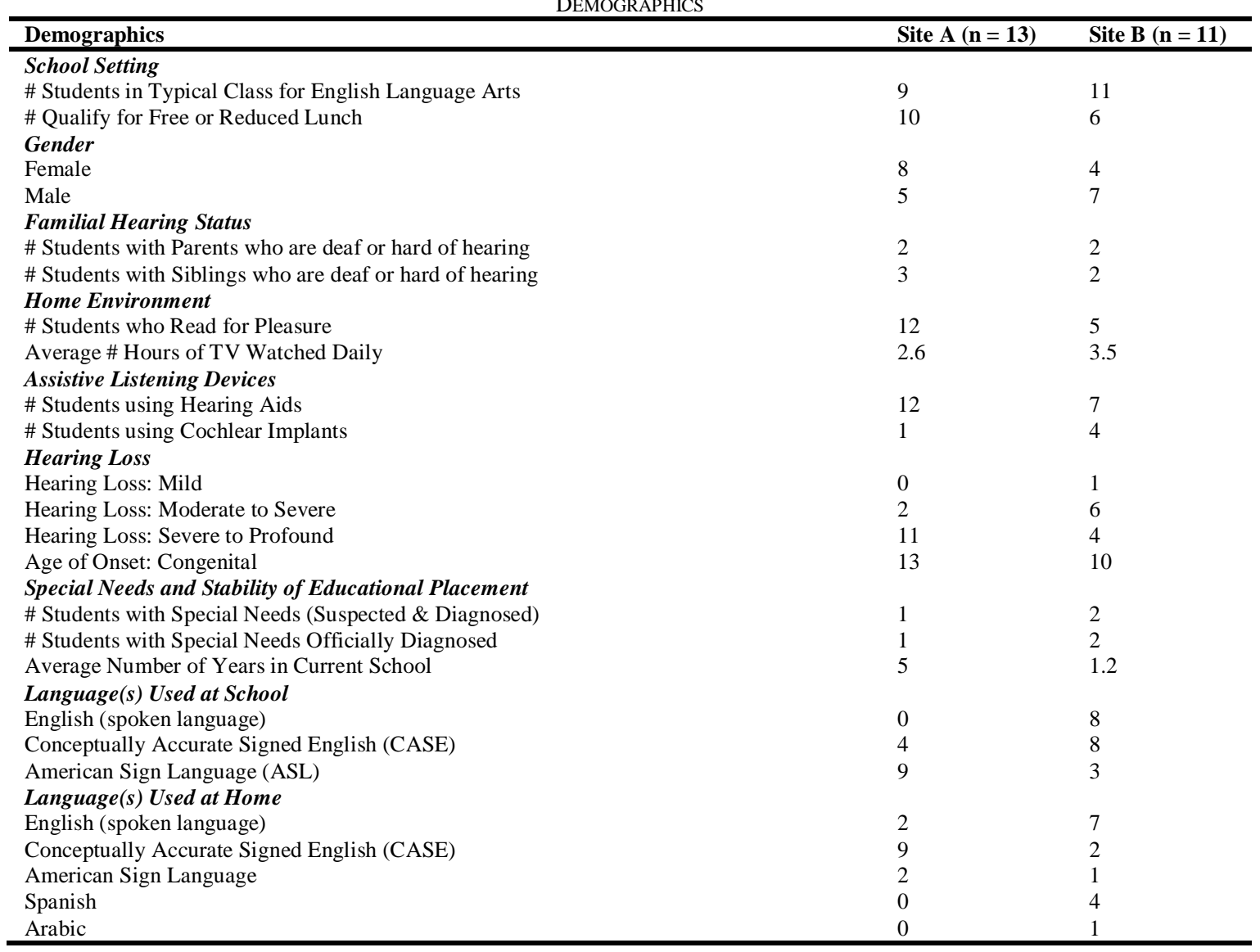

\section{Instrumentation}

Dependent means t-tests determined statistical significance of pre and post scores. Instruments used are criterion referenced tests provided within the FV protocols, which are curriculum-based, criterion referenced assessments. The Adapted Dolch Word lists, Bridge Lists, and Phonemic Awareness Patterns are pre/post identification tests. Reading comprehension levels are teacher reports of functional reading assessments used by their respective school programs. The SRA Multiple Skills Series (MSS) was utilized by Teacher A to supplement guided reading instruction as well as to measure reading comprehension, at various levels of scaffolded support. Site B utilized the Scholastic Reading Inventory (SRI), a research-based, computer-adaptive reading assessment program for students in Grades $\mathrm{K}-12$, to measure reading comprehension. Language samples, both in written English and in American Sign Language, are rubric-based assessments that track individual progression exhibited in point-in-time work samples.

\section{Intervention}

Both teachers are highly trained in the FV protocols, yet they emphasize the FV components differently in their respective classes. Teacher A is the reading teacher, so she emphasizes four of the FV components - Adapted Dolch words, Bridge Lists, literature-based instruction, and phonemic awareness - approximately one hour each day, rotating emphasis on the four different components through the use of small group and center work. Two other teachers at Teacher A's school are responsible for ASL development and spontaneous written English; however, pre and post assessments on those two measures were still collected. Teacher B teaches writing to her middle school students in addition to reading; therefore, she uses four of the FV components - Adapted Dolch Words, Bridge Lists, literaturebased instruction, ASL development and Spontaneous Written English. Teacher B's structured approach to the Bridge Lists systematically integrates these phrases and the Adapted Dolch Words into her reading and writing materials. She spends approximately two hours each day rotating emphasis on four different components through the use of small group and center work.

\section{RESULTS}

Dependent means t-tests determined the statistical significance and identified differences in individual pre- and posttest results. These t-tests were selected due to the nature of the data and to help control for extraneous and unknown sources of variation. Students were treated as their own controls in order to measure gain in literacy levels. The unit of measure in the pair $t$ was thus the difference in the individual's pre- and post-test results for each measure recorded.

Component 1: Adapted Dolch Words 
Researchers collected pre and post-test scores for participating students on the four levels of the Adapted Dolch and total scores. Percent change from pre to post testing was calculated. The percent increase scores are significant. Figure 2 provides a visual depiction of scores, clearly identifying a consistent trend among students. A dependent means t-test, which utilizes difference scores $(\bar{X}=264.17$; SD $=138.60)$ determined the statistical significance of pre and post testing results. The paired t test was used to analyze and identify differences in individual pre- and post-test results and was selected due to the nature of the data as well as to help control for extraneous and unknown sources of variation. Students were treated as their own controls in order to measure gain in literacy levels. The unit of measure in the pair $t$ was thus the difference in the individual's pre- and post-test results for each measure recorded. The impact of this portion of the intervention was statistically significant at each subtest and for the total pre/post comparison, $(\mathrm{t}(23)=$ 9.34, $\mathrm{p}=.00)$; see Table 2 .

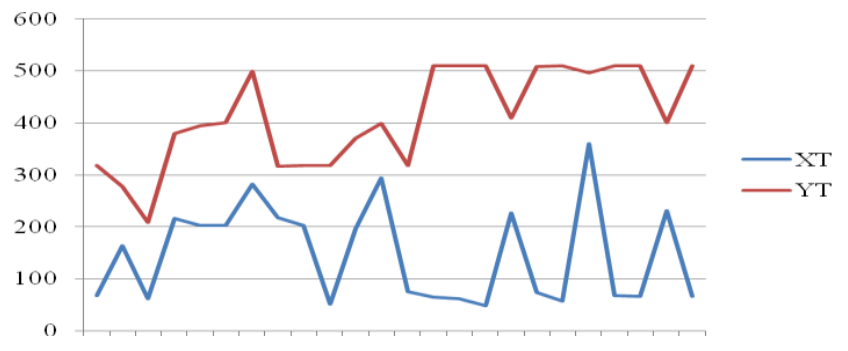

Figure 2: Adapted Dolch Component, Individual Scores

TABLE 2:

\begin{tabular}{|c|c|c|c|c|c|c|}
\hline \multirow{2}{*}{$\begin{array}{l}\text { Adapted Dolch } \\
\text { Subtest }\end{array}$} & \multicolumn{4}{|l|}{$\bar{X}$} & \multirow[b]{2}{*}{$\mathrm{t}$} & \multirow[b]{2}{*}{ df } \\
\hline & $\mathrm{n}$ & Pre & Post & Difference & & \\
\hline Preprimer & 24 & $\begin{array}{l}57.50 \\
(19.44)\end{array}$ & $\begin{array}{l}92.92 \\
(5.09)\end{array}$ & $\begin{array}{l}35.42 \\
(18.42)\end{array}$ & $9.42 * *$ & 23 \\
\hline Primer & 24 & $\begin{array}{l}36.38 \\
(39.76)\end{array}$ & $\begin{array}{l}113.00 \\
(0.00)\end{array}$ & $\begin{array}{l}76.63 \\
(39.76)\end{array}$ & $9.44 * *$ & 23 \\
\hline $1^{\text {st }}$ Grade & 24 & $\begin{array}{l}23.71 \\
27.36\end{array}$ & $\begin{array}{l}103.75 \\
(23.09)\end{array}$ & $\begin{array}{l}80.04 \\
(33.79)\end{array}$ & $11.61 * *$ & 23 \\
\hline $2^{\text {nd }}$ Grade & 24 & $\begin{array}{l}26.50 \\
(32.33)\end{array}$ & $\begin{array}{l}70.13 \\
(47.86)\end{array}$ & $\begin{array}{l}43.63 \\
(53.03)\end{array}$ & $4.03 * *$ & 23 \\
\hline $3^{\text {rd }}$ Grade & 24 & $\begin{array}{l}4.25 \\
(14.40)\end{array}$ & $\begin{array}{l}32.75 \\
(39.63)\end{array}$ & $\begin{array}{l}28.50 \\
(37.70)\end{array}$ & $3.70 * *$ & 23 \\
\hline Total & 24 & $\begin{array}{l}148.33 \\
(94.34)\end{array}$ & $\begin{array}{l}412.50 \\
(93.07)\end{array}$ & $\begin{array}{l}264.17 \\
(138.60)\end{array}$ & $9.34 * *$ & 23 \\
\hline
\end{tabular}

\section{Component 2: Reading Comprehension and the Bridging Process}

Statistical measures, described for the Adapted Dolch were repeated in this component. Figure 3 provides a visual depiction of scores, clearly identifying a consistent trend among students. A dependent means t-test, which utilizes difference scores $(\bar{X}=351.42 ; \mathrm{SD}=144.94)$ determined statistical significance of pre and post testing results. The impact of this portion of the intervention was statistically significant at each subtest and for the overall pre/post difference $(\mathrm{t}(23)=11.88, \mathrm{p}=.00)$; see Table 3 .

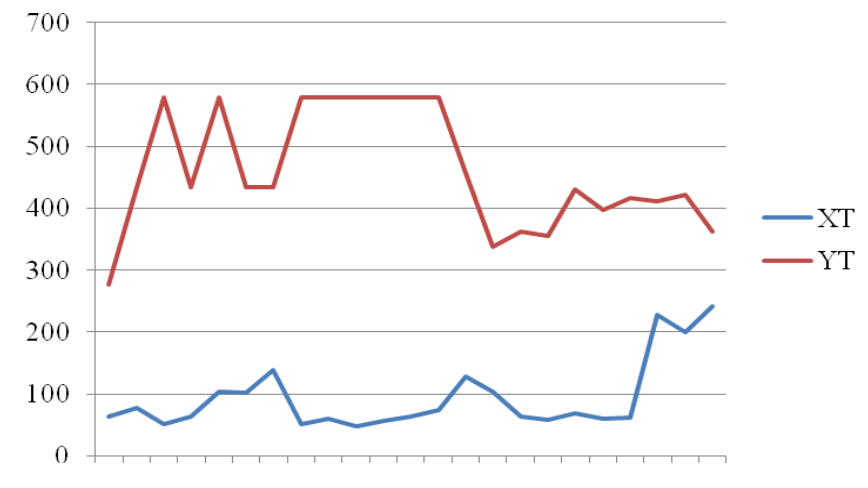

Figure 3: Bridging Component, Individual Scores 
TABLE 3:

BRIDGING COMPONENT, DEPENDENT MEANS T-TEST

\begin{tabular}{|c|c|c|c|c|c|c|}
\hline \multirow{2}{*}{ Bridging Subtest } & \multicolumn{4}{|l|}{$\bar{X}$} & \multirow[b]{2}{*}{$\mathrm{t}$} & \multirow[b]{2}{*}{ df } \\
\hline & $\mathrm{n}$ & Pre & Post & Difference & & \\
\hline Preprimer & 24 & $\begin{array}{l}58.58 \\
(43.30)\end{array}$ & $\begin{array}{l}151.67 \\
(5.74)\end{array}$ & $\begin{array}{l}93.08 \\
(45.16)\end{array}$ & $10.10 * *$ & 23 \\
\hline Primer & 24 & $\begin{array}{l}20.42 \\
(28.91)\end{array}$ & $\begin{array}{l}119.54 \\
(15.89)\end{array}$ & $\begin{array}{l}99.13 \\
(35.66)\end{array}$ & $13.62 * *$ & 23 \\
\hline $1^{\text {st }}$ Grade & 24 & $\begin{array}{l}17.71 \\
(24.13)\end{array}$ & $\begin{array}{l}129.71 \\
(44.65)\end{array}$ & $\begin{array}{l}112.00 \\
(55.18)\end{array}$ & $9.94 * *$ & 23 \\
\hline $2^{\text {nd }}$ Grade & 24 & $\begin{array}{l}2.71 \\
(7.65)\end{array}$ & $\begin{array}{l}24.92 \\
(33.03)\end{array}$ & $\begin{array}{l}22.21 \\
(34.95)\end{array}$ & $3.11 * *$ & 23 \\
\hline $3^{\text {rd }}$ Grade & 24 & $\begin{array}{l}0.00 \\
(0.00)\end{array}$ & $\begin{array}{l}25.00 \\
(36.12)\end{array}$ & $\begin{array}{l}25.00 \\
(36.12)\end{array}$ & $3.34 * *$ & 23 \\
\hline Total & 24 & $\begin{array}{l}99.42 \\
(61.62)\end{array}$ & $\begin{array}{l}450.83 \\
(106.09)\end{array}$ & $\begin{array}{l}351.42 \\
(144.94)\end{array}$ & $11.88 * *$ & 23 \\
\hline
\end{tabular}

**Significant at the 0.01 level (2-tailed)

* Significant at the 0.05 level (2-tailed).

\section{Component 3: Phonemic Awareness}

Teacher A utilized the phonemic awareness component, but Teacher B did not. As Figure 4 demonstrates, students mastered the 42 consonant sounds and vowel patterns. However, pretest scores suggest that these students had no previous exposure to these phonological patterns. As with the other components, a dependent means t-test, which utilizes difference scores $(\bar{X}=42.92 ; \mathrm{SD}=0.29)$ was used to determine statistical significance. Both consonants and the total pre/post difference $(\mathrm{t}(11)=503.00, \mathrm{p}=.00)$ were statistically significant at a $99 \%$ confidence interval. See Table 4 . Note that there was no deviation in scores among students in the groups for long and short vowel patterns; all students moved from 0 to 5 and 0 to 16 respectively. With no deviation in scores, a t-test could not be appropriately utilized.

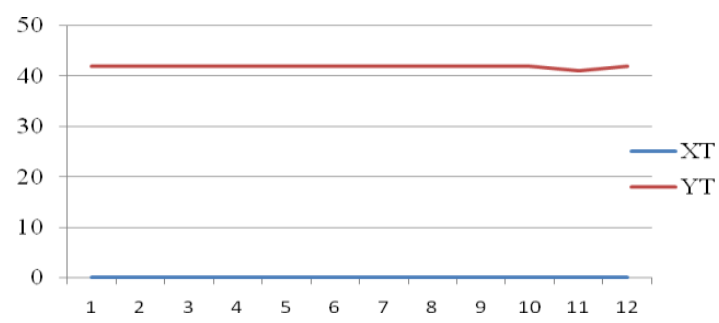

Figure 4: Phonemic Awareness Component, Individual Scores

TABLE 4:

Phonemic AwARENESS COMPONENT, DEPENDENT MEANS T-TeSt

\begin{tabular}{|c|c|c|c|c|c|c|}
\hline \multirow{2}{*}{$\begin{array}{l}\text { Phonemic Awareness } \\
\text { Subtest }\end{array}$} & \multicolumn{4}{|l|}{$\bar{X}$} & \multirow[b]{2}{*}{$\mathrm{t}$} & \multirow[b]{2}{*}{$\mathrm{df}$} \\
\hline & $\mathrm{n}$ & Pre & Post & Difference & & \\
\hline Consonants & 12 & $\begin{array}{l}0.00 \\
(0.00)\end{array}$ & $\begin{array}{l}20.92 \\
(0.29)\end{array}$ & $\begin{array}{l}20.92 \\
(0.29)\end{array}$ & $251.00 * *$ & 11 \\
\hline Long & 12 & $\begin{array}{l}0.00 \\
(0.00)\end{array}$ & $\begin{array}{l}5.00 \\
(0.00)\end{array}$ & $\begin{array}{l}5.00 \\
(0.00)\end{array}$ & NA & NA \\
\hline Short & 12 & $\begin{array}{l}0.00 \\
(0.00)\end{array}$ & $\begin{array}{l}16.00 \\
(0.00)\end{array}$ & $\begin{array}{l}16.00 \\
(0.00)\end{array}$ & NA & NA \\
\hline Total & 12 & $\begin{array}{l}0.00 \\
(0.00)\end{array}$ & $\begin{array}{l}42.92 \\
(0.29)\end{array}$ & $\begin{array}{l}42.92 \\
(0.29)\end{array}$ & $503.00 * *$ & 11 \\
\hline
\end{tabular}

\section{Component 4: Literature-Based Instruction}

As Figure 5 demonstrates, all students improved their reading abilities. Although scores should be critically evaluated individually given the large standard deviation in post-testing, the pre-test mean for the two samples was at a second grade level $(\bar{X}=2.38 ; \mathrm{SD}=0.94)$ and improved to a fifth grade level $(\bar{X}=5.50 ; \mathrm{SD}=3.61)$ in post testing. When considering individual scores, only five students improved less than one grade level during the academic year. Every student was at risk, being at least two grade levels behind their academic grade placement in their pretests and had never improved a full grade level in one academic year. These results show promise for Fairview's efficacy as an RTI protocol. A dependent means t-test determined statistical significance $(t(19)=9.37, \mathrm{p}=.00)$. See Table 5 . 


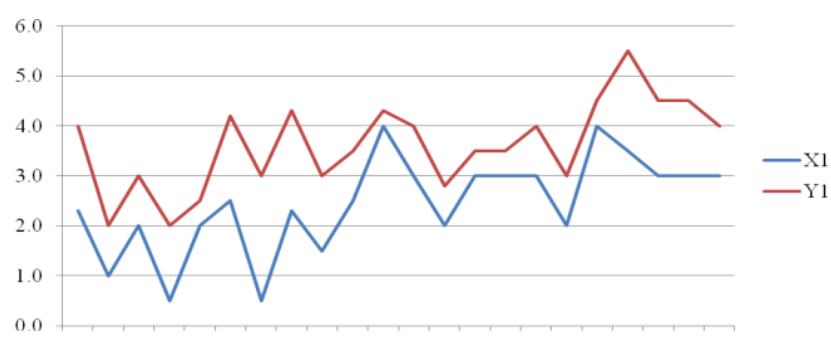

Figure 5: Reading Comprehension, Individual Scores

TABLE 5:

READING COMPREHENSION, DEPENDENT MEANS T-TEST

\begin{tabular}{|c|c|c|c|c|c|c|}
\hline \multirow{2}{*}{$\begin{array}{l}\text { Reading } \\
\text { Comprehension }\end{array}$} & \multicolumn{4}{|l|}{$\bar{X}$} & \multirow[b]{2}{*}{$\mathrm{t}$} & \multirow[b]{2}{*}{ df } \\
\hline & $\mathrm{n}$ & Pre & Post & Difference & & \\
\hline Reading Comp & 20 & $\begin{array}{l}2.38 \\
(0.94)\end{array}$ & $\begin{array}{l}3.61 \\
(.90)\end{array}$ & $\begin{array}{l}1.23 \\
(0.58)\end{array}$ & $9.37 * *$ & 19 \\
\hline
\end{tabular}

\section{Component 5: ASL Development and Spontaneous Written English}

Teachers rate proficiencies regarding use of nouns, introductions, punctuation, use of complete sentences, prepositions, word order, staying on topic and use of adjectives and adverbs. As Figure 6 reveals, all students significantly improved their written language abilities $(\bar{X}=13.30 ; \mathrm{SD}=5.23)$. A dependent means t-test determined statistical significance in each subtest and in the overall pre/post total $(\mathrm{t}(9)=8.04, \mathrm{p}=.00)$. See Table 6 . Figures 7 and 8 provide a pre/post sample comparison for student \#14321.

Figure 9 and Table 7 provides pre and post American Sign Language scores for Teacher A's students. Teacher B did not directly teach this component. In this assessment, teachers rate student use of classifiers, ability to set up a story, facial expression, body language, verb usage, order, ability to stay on topic, and overall expression. Not all students improved but there was a mean increase $(\bar{X}=5.38 ; \mathrm{SD}=6.13)$ and scores on each subtest and on the total scale were statistically significant $(\mathrm{t}(12)=3.17, \mathrm{p}=.00)$.

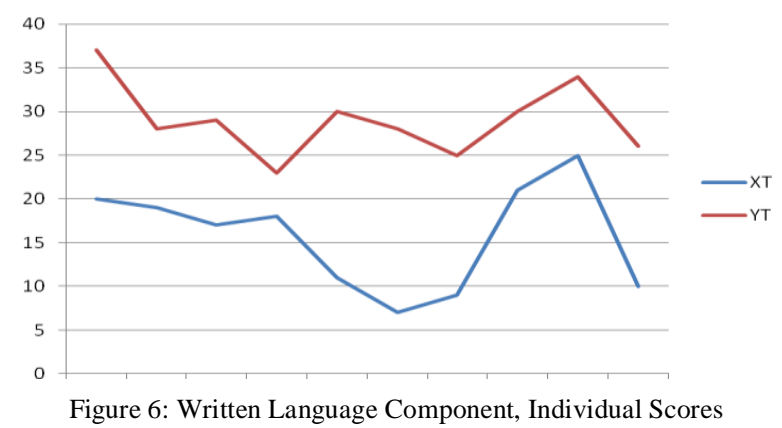

TABLE 6:

WritTEn LANGUAGE COMPONENT, DEPENDENT MEANS T-TEST

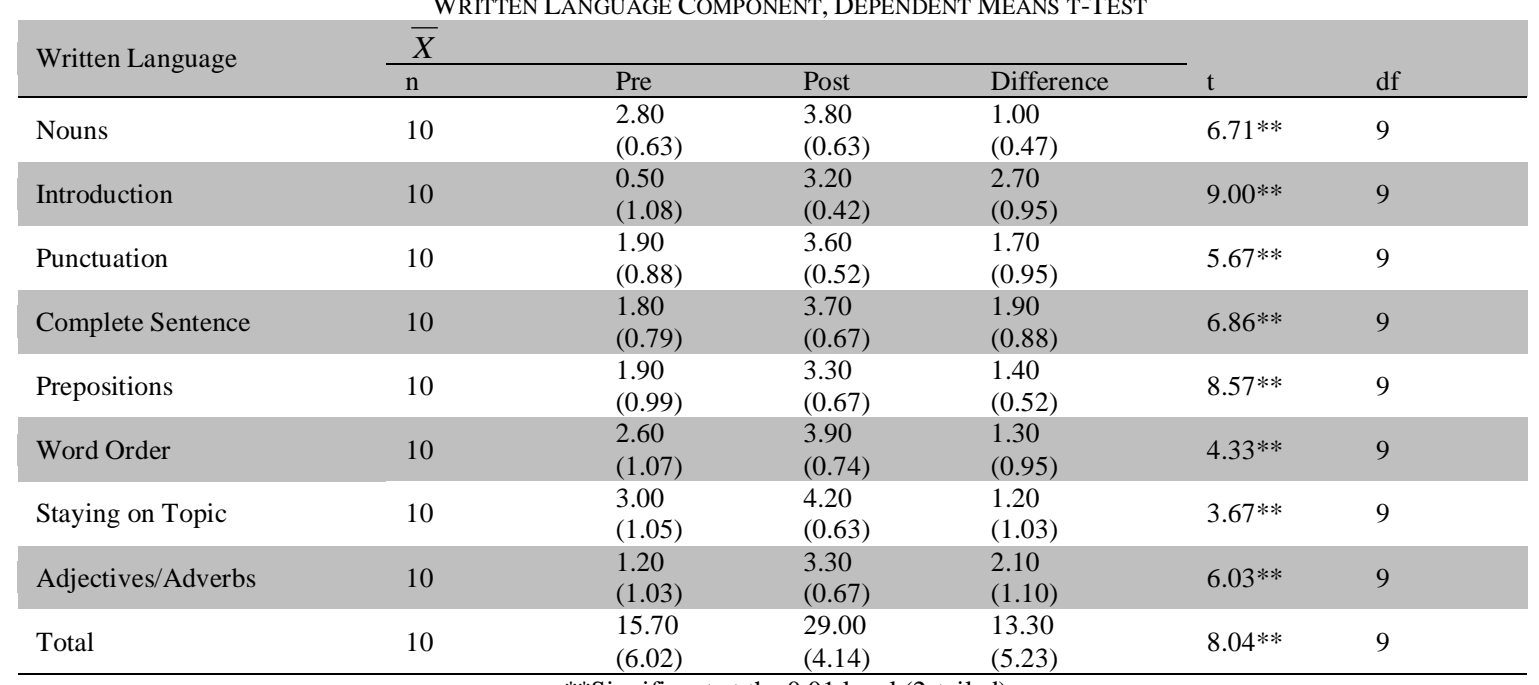

**Significant at the 0.01 level (2-tailed).

* Significant at the 0.05 level (2-tailed). 


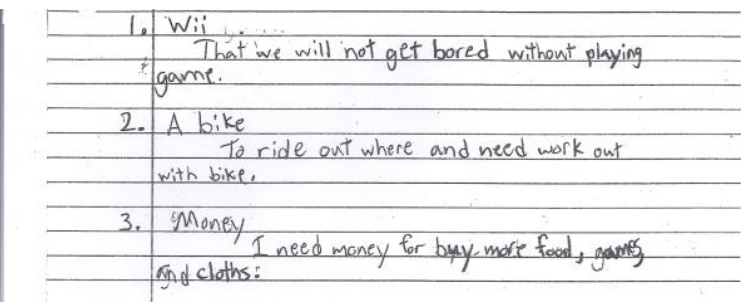

Figure 7: Student \#14321 Written Language, Pre-Intervention
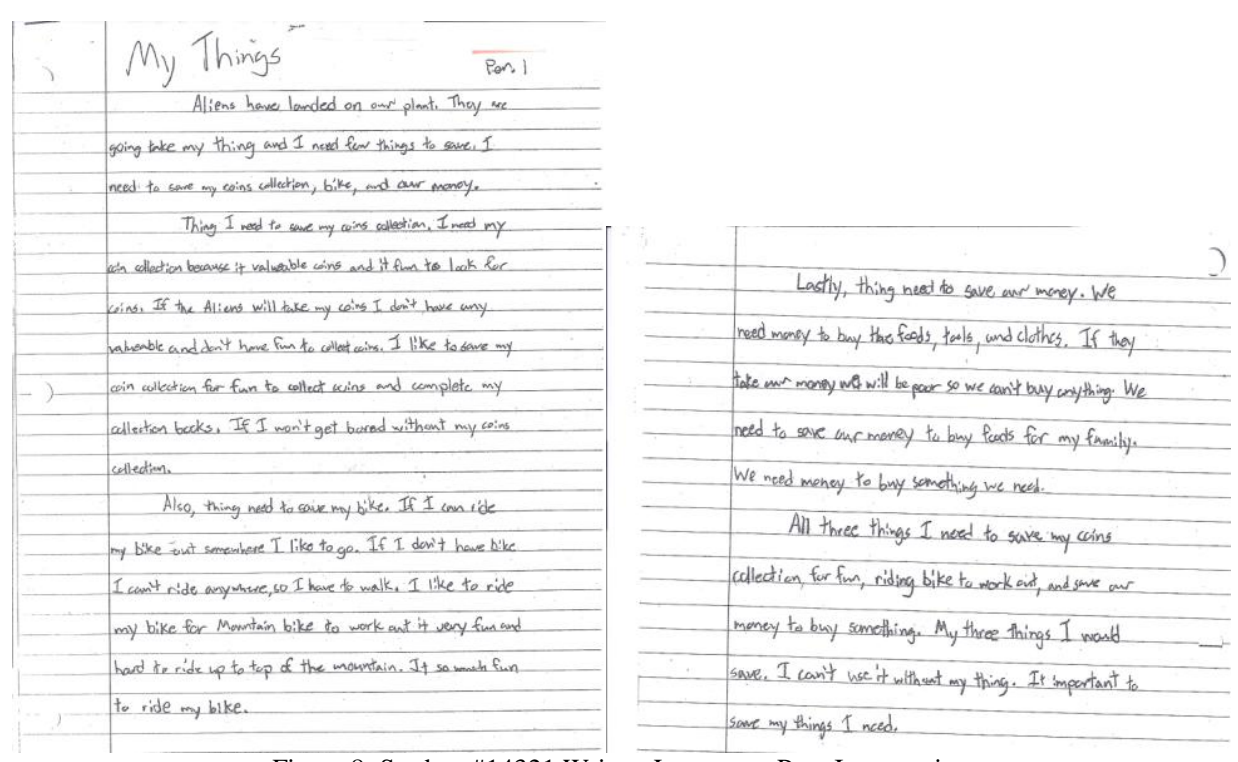

Figure 8: Student \#14321 Written Language, Post-Intervention

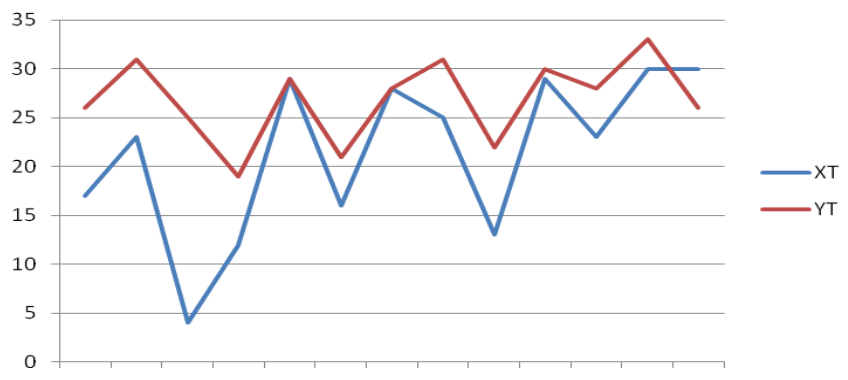

Figure 9: American Sign Language Component, Individual Scores

TABLE 7:

American Sign Language Component, DePendent Means t-TeSt

\begin{tabular}{|c|c|c|c|c|c|c|}
\hline \multirow{2}{*}{ Written Language } & \multicolumn{4}{|l|}{$\bar{X}$} & \multirow[b]{2}{*}{$\mathrm{t}$} & \multirow[b]{2}{*}{ df } \\
\hline & $\mathrm{n}$ & Pre & Post & Difference & & \\
\hline Classifiers & 13 & $\begin{array}{l}2.00 \\
(1.15)\end{array}$ & $\begin{array}{l}2.62 \\
(0.51)\end{array}$ & $\begin{array}{l}0.62 \\
(0.77)\end{array}$ & $2.89 * *$ & 12 \\
\hline Set Up & 13 & $\begin{array}{l}1.62 \\
(1.26)\end{array}$ & $\begin{array}{l}3.00 \\
(0.71)\end{array}$ & $\begin{array}{l}1.38 \\
(0.87)\end{array}$ & $5.74 * *$ & 12 \\
\hline Expression & 13 & $\begin{array}{l}3.08 \\
(0.95)\end{array}$ & $\begin{array}{l}3.69 \\
(0.63)\end{array}$ & $\begin{array}{l}0.62 \\
(0.65)\end{array}$ & $3.41 * *$ & 12 \\
\hline Body & 13 & $\begin{array}{l}3.00 \\
(0.91)\end{array}$ & $\begin{array}{l}3.77 \\
(0.60)\end{array}$ & $\begin{array}{l}0.77 \\
(0.60)\end{array}$ & $4.63 * *$ & 12 \\
\hline Verb & 13 & $\begin{array}{l}2.77 \\
(1.42)\end{array}$ & $\begin{array}{l}3.08 \\
(0.76)\end{array}$ & $\begin{array}{l}0.31 \\
(1.11)\end{array}$ & 1.00 & 12 \\
\hline Sign Order & 13 & $\begin{array}{l}3.31 \\
(0.85)\end{array}$ & $\begin{array}{l}2.92 \\
(0.49)\end{array}$ & $\begin{array}{l}-0.38 \\
(0.96)\end{array}$ & -1.44 & 12 \\
\hline Topic & 13 & $\begin{array}{l}3.46 \\
(0.88)\end{array}$ & $\begin{array}{l}4.08 \\
(1.04)\end{array}$ & $\begin{array}{l}0.62 \\
(1.39)\end{array}$ & 1.60 & 12 \\
\hline Expression & 13 & $\begin{array}{l}2.23 \\
(1.48)\end{array}$ & $\begin{array}{l}3.46 \\
(0.66)\end{array}$ & $\begin{array}{l}1.23 \\
(1.24)\end{array}$ & $3.59 * *$ & 12 \\
\hline Total & 13 & $\begin{array}{l}21.46 \\
(8.34)\end{array}$ & $\begin{array}{l}26.84 \\
(4.22)\end{array}$ & $\begin{array}{l}5.38 \\
(6.13)\end{array}$ & $3.17 * *$ & 12 \\
\hline
\end{tabular}

** Significant at the 0.01 level (2-tailed).

* Significant at the 0.05 level (2-tailed). 


\section{LIMITATIONS}

Fairview's approach provides systematic support for strategic language handling while respecting the individual teacher's professional expertise. FV provides assessment instruments for ASL development, and spontaneous written English. By design, there is local flexibility in the implementation and assessment approach for reading comprehension. In both school settings, obtaining reliable standardized measures of reading comprehension remained problematic. Teachers and administrators were reluctant to provide this data as scores were invalid, in their professional opinions. Actual data from standardized measures revealed inconsistent data trends and flawed results. This is not surprising given that accessibility and inequity in testing is a pervasive and systemic problem facing deaf educators across the United States (Mounty \& Martin, 2005).

Site A, the residential school site, administered the Test of Adult Basic Education (TABE) and the Mississippi Curriculum Test (MCT-2), both standardized measurements of Reading Comprehension, but no achievement patterns could be identified. With the TABE, teachers and administrators complained that the computerized delivery hindered student performance because students could not write on the test. With the MCT-2, students could write on the test, have the test pre-bridged, and have unlimited time; however, the test content construction is based on instructional levels of non-disabled students across the state. Site A also administered the Brigance, a functional assessment of reading, annually, but found scores to be inflated. In contrast to these other measures, the residential school selected the SRA Multiple Skills Series, a functional assessment, to determine actual reading comprehension ability to guide instructional planning, for they deemed it was the most accurate.

Site B, the public school site, had similar problems. The teacher reported that students entered her classroom with inflated scores from the vocabulary and reading subtests of the Woodcock-Johnson from other schools, especially for students with strong oral language, or as a result of variation in test administration (i.e., allowing parts of the tests to be signed) or via score interpretation, such as averaging several subtests which inflates scoring. Site B utilizes the Woodcock Johnson in three year cycles and students show growth. However, initial student scores did not consistently reflect students' functional reading ability. She reported this as a consistent trend. She was more comfortable with scores during exit testing using only the Woodcock-Johnson's reading passage comprehension subtest and states no accommodations were given. This teacher also used the Scholastic Reading Inventory (SRI) as yearly pre and post tests and felt the independent reading level provided was much more reflective of student ability. These are the scores reported by Teacher B. While entry Woodcock-Johnson scores were not consistent with initial SRI pre-tests, exit scores did correlate with the SRI post-tests.

The addition of standardized pre and post reading measures, such as the Stanford Achievement Test (SAT-HI, SAT-9, Stanford 10), the Diagnostic Assessment of Reading (DAR), or other standardized tests, are necessary to validate and compare student progress. Data-driven decisions require valid data, and the data must be from the same test given within a program. Another limitation in this study is that the teachers administered the pre and posttest assessments, potentially resulting in researcher bias.

\section{SUMMARY}

The FV intervention program provides a structured approach to assist deaf students with reading. The program illuminates connections between English print and ASL through the use of conceptually accurate signing, code switching, and explicit teaching techniques and tools. Consistent and significant outcomes result when teachers fully implement the FV protocol and consistently and accurately assess student progress. The use of FV as RTI or as an informal reading inventory is a promising technique in programs serving deaf students, but its true impact can only be truly determined through additional rigorous research. Nevertheless, FV remains one of the few protocols that strategically address the three domains for bimodal bilinguals, with heavy emphasis on reading comprehension. While the FV components critically align with research and best practices in ASL/English bilingual education, the data presented herein should still be considered preliminary. Future research of a large scale nature, across delivery options, is needed to determine generalizability of results. Future studies should address reading comprehension protocols at the outset and decide upon a standardized method; in addition, fidelity of implementation and consideration of language handling differences should be delineated. Determination of effectiveness between and across school sites, teacher implementation, and educational settings would also be useful as this study did not compare the results of students between the two sites. While large scale future studies are necessary to further our understanding of effective techniques, the protocols show promise for increasing achievement in reading and assisting students in breaking beyond the fourth grade plateau effect by providing them with systematic tools to attack English print.

\section{REFERENCES}

[1] Andrews, J. F., Leigh, I. W., \& Weiner, M. T. (2004). Deaf people: Evolving perspectives in psychology, education and sociology. Boston, MA: Allyn and Bacon.

[2] Andrews, J.F., \& Karlin, A. (1996). Reading behaviors of deaf bilingual college students. JADARA, 36(1), 28-44.

[3] Andrews, J.F. \& Rusher, M. (2010). Codeswitching techniques: Evidence-based practices for the ASL/English bilingual classroom. American Annals for the Deaf, 155(4), 407-424. 
[4] Ausbrooks, M. (2007). Predictors of reading success among deaf bilinguals: Examining the relationship between American Sign Language and English. Beaumont, TX: Lamar University.

[5] Ausbrooks Rusher, M. (2012, in press) Title: Language interdependence between American Sign Language and English: A review of empirical studies. ERIC (ED530276).

[6] Bailes, C. (2001). Integrative ASL-English language arts: Bridging paths to literacy. Sign Language Studies, 1(2), 147-174.

[7] Baker, C., \& Jones, S. P. (1998). Encyclopedia of bilingualism and bilingual education. Clevedon, England: Multilingual Matters, Inc.

[8] Bradley, R., Danielson, L, and Doolittle, J. (2007). Responsiveness to intervention: 1997 to 2007. Teaching Exceptional Children, May/June, Vol. 39, No. 5, 8-12.

[9] Charrow, V.R. (1981). The written English of deaf adolescents. In M.F. Whiteman (Ed.), Writing: The nature, development, and teaching of written communication. Vol. 1. (pp. 179-187). Hillsdale, NJ: Lawrence Erlbaum Associates.

[10] Cummins, J. (1979). Linguistic interdependence and the educational development of bilingual children. Review of Educational Research, 49, 222-251.

[11] Cummins, J. (2000). Language, power, and pedagogy: Bilingual children in the crossfire. Buffalo, NY: Multilingual Matters Ltd.

[12] Cummins, J. (2007). The relationship between American Sign Language proficiency and English academic development: A review of the research. Retrieved June 15, 2009 from http://aslthinktank.com/files/CumminsASL-Eng.pd

[13] Davis, H. \& Silverman, R. (1966). Hearing and deafness. New York: Holt, Rinehart, and Winston.

[14] Dehaene, (2009). Reading in the brain. New York: Viking Penguin, p. 219.

[15] DeLana, M., Gentry, M., \& Andrews, J. (2008). The efficacy of ASL/English bilingual education: Investigating public schools. American Annals of the Deaf, 152(1), 73-87.

[16] Dixon, C. (1990). Language Experience Approach to Reading (And Writing): LEA for ESL .Prentice Hall.

[17] Easterbrooks, S. R., Lederberg, A. R., Miller, E. M., Bergeron, J. P., \& Connor, C. M. (2008). Emergent literacy skills during earlychildhood in children with hearing loss: Strengths and weaknesses. Volta Review, 108(2), 91-114.

[18] Frishberg, N. (2000). An interpreter creates the space. In K. Emmorey \& H. Lane (Eds.), The signs of language revisited: An anthology to honor Ursula Bellugi and Edward Klima (pp. 169-192). Mahweh, NJ: Lawrence Erlbaum.

[19] Fuchs, D., Fuchs, L.S., Compton, D.L., Bouton, B., Caffrey, E., \& Hill, L. (2007). Dynamic assessment as responsiveness to intervention. Teaching Exceptional Children, 39(5), 58- 63.

[20] Garcia, O. (2009). Bilingual education in the $21^{\text {st }}$ century: A global perspective. Malden, MA: Wiley-Blackwell.

[21] Goldman-Meadow, S. \& Mayberry, R. (2001). How do profoundly deaf children learn to read? Learning Disabilities Research \& Practice, 16(4), 222-229.

[22] Grosjean, F. (1998). Living with two languages and cultures. In I. Parasnis (Ed.), Culture and language diversity and the deaf experience (pp. 20-37). New York: Cambridge University Press.

[23] Haskins, B. (2000). Serving and assessing deaf patients: Implications for Psychiatry. Psychiatric Times, XVII(12), 29-32.

[24] Hauser, P. C. (2000). Code switching: American Sign Language and cued English. In M. Metzger (Ed.), Bilingualism and identity in Deaf communities (pp. 43-78). Washington, DC: Gallaudet University Press.

[25] Hoffmeister, R. J. (2000). A piece of the puzzle: ASL and reading comprehension in deaf children. In C. Chamberlain, J. P. Morford \& R. Mayberry (Eds.), Language acquisition by eye (pp. 143-163). Mahwah, NJ: Lawrence Erlbaum Publishers.

[26] Johnson, R., Liddell, S., \& Erting, C. (1989). Unlocking the curriculum. Washington, D.C.: Gallaudet Research Institute.

[27] Johnson, J., Watkins, R., \& Rice, M. (1992). Bimodal bilingual language development in a hearing child of deaf parents. Applied Psycholinguistics, (13), 31-52.

[28] Kame'enui, E. (2007). A new paradigm, responsiveness to intervention. Teaching Exceptional Children, May/June, Vol. 39, No. 5, 6-7.

[29] Kyle, F. E., \& Harris, M. (2006). Concurrent correlates and predictors of reading and spelling achievement in deaf and hearing school children. Journal of Deaf Studies and Deaf Education, 11(3), 273-288.

[30] Larson, M. L. (1994). Translation and linguistic theory. In R. E. Asher (Ed.), The Encyclopedia of language and linguistics, Volume 9 (pp. 4685-4694). Oxford and Tarrytown, NY: Pergamon Press.

[31] Lartz, M., \& Lestina, L. (1995). Strategies deaf mothers use when reading to their young deaf or hard of hearing children. American Annals of the Deaf, 140(4), 358-362.

[32] LaSasso, C., \& Lollis, J. (2003). Survey of residential and day schools for deaf students in the United States that identify themselves as bilingual-bicultural programs. Journal of Deaf Studies and Deaf Education, 8(1), 79-91.

[33] Lieberman, P. (2000). Human language and our reptilian brain: the subcortical bases of speech, syntax, and thought. Cambridge, MA: Harvard University Press

[34] Livingston, S. (1997). Rethinking the education of deaf students: Theory and practice from a teacher's perspective. Portsmouth, NH: Heinemann.

[35] Mather, S., \& Thibeault, A. (2000). Creating an involvement-focused style in book reading with deaf and hard of hearing students: The visual way. In C. Chamberlain, J. P., Morford \& R. Mayberry (Eds.), Language acquisition by eye (pp. 191-220). Mahwah, NJ: Lawrence Erlbaum Publishers.

[36] Mayer, C. (2007). What really matters in the early literacy development of deaf children. Journal of Deaf Studies and Deaf Education 12(4), 413-431.

[37] Mayer, C., \& Akamatsu, C. T. (November 30, 1998). Bilingual-bicultural models of literacy education for deaf students: considering the claims. Journal of Deaf Studies and Deaf Education, 4, 1-8.

[38] Mayer, C., \& Akamatsu, C.T. (2003). Bilingualism and literacy. In M. Marschark \& P.E. Spencer (Eds.), Deaf studies, language, and education (pp. 136-147). New York, NY: Oxford University Press.

[39] Mayer, C., \& Akamatsu, T. (2010). Bilingualism and literacy. In M. Marschark \& P. Spencer (Eds.), The Oxford handbook of deaf studies, language, and education (Vol. 1; 2nd ed.) (pp. 144-155). New York, NY: Oxford University Press. 
[40] Mayer, C., \& Wells, G. (1996). Can the linguistic interdependence theory support a bilingual-bicultural model of literacy education for deaf students? Journal of Deaf Studies and Deaf Education, 1, 93-107.

[41] McQuarrie, L., \& Parrila, R. K. (2009). Deaf children's awareness of phonological structure: Rethinking the 'functional equivalence' hypothesis. Journal of Deaf Studies and Deaf Education. 14(2):137-154.

[42] Mitchell, R., \& Karchmer, M. A. (2004). Chasing the mythical ten percent: Parental hearing status of deaf and hard of hearing students in the United States. Sign Language Studies (4)2, pp. 138-163.

[43] Mounty, J. L., \& Martin, D. S. (2005). Assessing deaf adults: Critical issues in testing and evaluation. Washington, D.C: Gallaudet University Press.

[44] Myers, M. (2011). The relationship between English reading comprehension scores and years enrolled at a residential school for the deaf. Unpublished dissertation. Beaumont, TX: Lamar University.

[45] National Reading Panel. (2001). Teaching children to read, an evidence-based assessment of the scientific research literature on reading and its implications for reading instruction. National Institute for Literacy.

[46] Nover, S. (2006, February). Language Planning. Paper presented at the Association of College Educators of the Deaf and Hard of Hearing, Denver, Colorado.

[47] Nover, S., Andrews, J., Baker, S., Everhart, V., \& Bradford, M. (2002). Staff development in ASL/English bilingual instruction for deaf students: Evaluation and impact study. USDLC Star Schools project report no. 5. Retrieved May 16, 2005, from http://www.nmsd.k12.nm.us/caeber/documents/year5.pdf

[48] Nover, S., Christensen, K., \& Cheng, L. (1998). Development of ASL and English competence for learners who are deaf. Topics in Language Disorders, 18(4), 61-72.

[49] Nover, S., \& Moll, L. (1997). Cultural mediation of deaf cognition. In M. P. Moeller \& B. Schick (Eds.), Deafness and diversity: Sociolinguistics issues (pp. 39-50). Omaha, NE: Boys Town National Research Hospital.

[50] Padden, C. (1998). From the cultural to the bicultural: The modern deaf community. In I. Parasnis (Ed.), Culture and language diversity and the deaf experience. New York, NY: Cambridge University Press.

[51] Pinker, S. (1998). How the Mind Works. Salt Lake City, UT: Science News. 155(2).

[52] Rayner, K., Foorman, B., Perfetti, C., Pesetsky, D., and Seidenberg, M. (2002). How Should Reading Be Taught? Scientific American. March: 85-91.

[53] Sidelnick, M. \& Svoboda, M, (2000). The bridge between drawing and writing: Hannah's story. The Reading Teacher, Vol 54, No. 2, October, 174-184.

[54] Schleper, D. (2002). Leading from Behind: Language Experience in Action. Washington, DC: Gallaudet University, Laurent Clerc National Deaf Education Center.

[55] Schimmel, C.S. (2010). Owner and CEO of Fairview Learning, Personal Communication, May 10, 2010.

[56] Schirmer, B. (2000). Language and literacy development in children who are deaf. Needham Heights, MA: Allyn and Bacon.

[57] Singleton, J.L, Supalla, S., Litchfield, S., Schley, S. (1998). From sign to word: Considering modality constraints in ASL/English bilingual education. Topics in Language Disorders, 18(4), 16-29.

[58] Stokoe, William C. (1960). Sign language structure: An outline of the visual communication systems of the American deaf. Studies in linguistics: Occasional papers (No. 8). Buffalo: Dept. of Anthropology and Linguistics, University of Buffalo.

[59] Stokoe, W. (1976). The study and use of sign language. Sign Language Studies, 10, 1-36.

[60] Syverud, S. Guardino, C. \& Selznick, D. (2009) . Teaching Phonological Skills to a Deaf First Grader: A Promising Strategy. American Annals of the Deaf, Fall, 154 (4).

[61] Traxler, C.B. (2002). Measuring up to performance standards in reading and mathematics: Achievement of selected deaf and hard of hearing students in the national norming of the Ninth Edition Stanford Achievement Test, Journal of Deaf Studies and Deaf Education, 5, 337-348.

[62] Trezek, B., Wang, Y, \& Paul, P. (2010). Reading and deafness: Theory, research, and practice. Clifton Park, New York: Delmar, Cengage Learning.

[63] Wang, Y., Trezek, B., Luckner, J. \& Paul, P. (2008). The role of phonology and phonologically related skills in reading instruction for students who are deaf or hard of hearing. American annals of the Deaf, Fall, 153(4), 396-407.

[64] Valli, C., \& Lucas, C. (2000). Linguistics of American Sign Language: An introduction. Washington, D.C: Gallaudet University Press.

Melissa Ausbrooks-Rusher is an Assistant Professor of Deaf Studies/Deaf Education at Lamar University in Beaumont, TX. A former classroom teacher of deaf students, she prepares masters-level teachers and doctoral-level educational leaders for bilingual programs.

Connie Schimmel is Emerita Associate Professor of Education at Millsaps College in Jackson, MS. Schimmel is also the founder and CEO of Fairview.

Sandra Edwards, a CODA, is Superintendent at the Mississippi School for the Deaf. Edwards worked with Schimmel in the initial development of the Fairview strategies and its early implementation. 